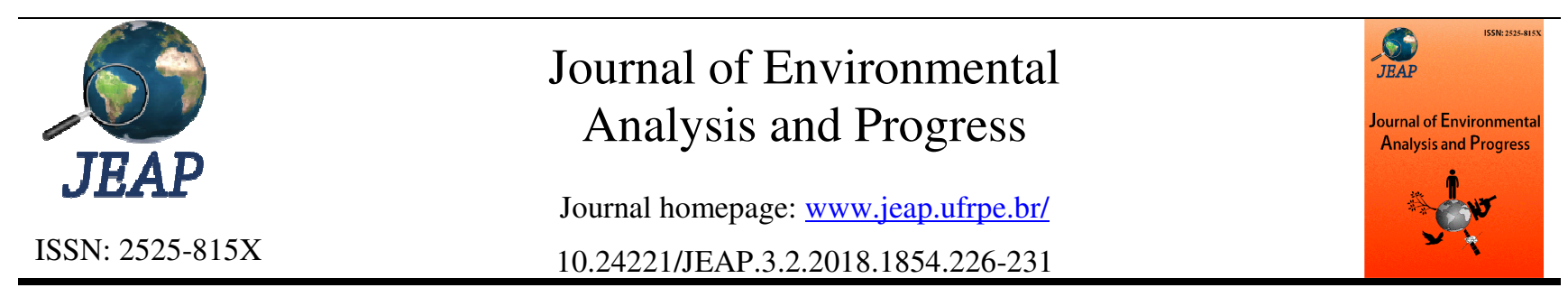

\title{
Análise microbiológica em goma de mandioca industrializada
}

\section{Microbiological analysis in industrialized cassava gum}

Neide Kazue Sakugawa Shinohara ${ }^{a}$, Maria de Fátima do Rosário Padilha ${ }^{a}$ Indira Maria Estolano Macêdo $^{\mathrm{a}}$, Kessia Catarina Barboza de Lima Nascimento ${ }^{\mathrm{b}}$, Mario Vila Nova Campos ${ }^{\mathrm{c}}$, Carine Ádila Cunha Melo Campos ${ }^{\mathrm{d}}$.

${ }^{\text {a }}$ Universidade Federal Rural de Pernambuco-UFRPE, Departamento de Tecnologia Rural, Laboratório dos Alimentos e Laboratório de Microbiologia Ambiental, Rua Dom Manoel de Medeiros, SN, Dois Irmãos, Pernambuco, Brasil. CEP: 52171-900. E-mail: neideshinohara@gmail.com, padilhamrf@gmail.com, indiramacedo21@ gmail.com.

b Centro Universitário Uninassau, Rua Guilherme Pinto, Graças, Recife-PE, Brasil. CEP: 52010-210. E-mail: kessia_catarina@hotmail.com.

${ }^{\mathrm{c}}$ Faculdade Integrada do Recife-FACIPE, Av. Caxangá, 4477, Várzea, Recife - PE, Brasil. CEP: 50740-000. E-mail: mariovncampos@hotmail.com.

${ }^{\mathrm{d}}$ Universidade Federal de Pernambuco-UFPE, Av. Prof. Moraes Rego, n. 1235, Cidade Universitária, Recife-PE, Brasil. CEP: 50670-901. E-mail: carine_adila@ hotmail.com.

\begin{abstract}
A R T I C L E I N F O
Recebido 18 Mar 2018

Aceito 20 Abr 2018

Publicado 24 Abr 2018

A B S T R A C T

Tapioca gum, derived from cassava is a product free of gluten, culturally there is great consumption in the Brazilian Northeast and has increased along with other Brazilian regions. The objective of this study was to evaluate the quality parameters of tapioca gums commercialized in the Metropolitan Region of Recife/PE. Sixteen samples of tapioca gum were obtained from supermarkets and tests were carried out for the detection of thermotolerant coliform; Bacillus cereus; Salmonella sp.; mesophilic Total Count; Molds and Yeasts and Lactic Bacteria. Among all the samples, three of them presented concentrations of thermotolerant coliform above the allowed amount for commercialization. All 16 samples analyzed were safe for consumption, as they did not present contamination in concentrations above that prevailing in the current legislation. An interesting finding was the presence of lactic bacteria in all samples, because the growth of this microorganism favors the conservation of tapioca gum, due to the ability to produce lactic acid, a compound that inhibits the growth of the accompanying microbiota, among which pathogenic microorganisms.
\end{abstract}

Keywords: Manihot, starch, lacticbacteria. coliform, microorganisms.

\section{R E S U M O}

A goma de tapioca, derivado da mandioca é um produto isento de glúten, culturalmente há grande consumo no Nordeste brasileiro e tem aumentado junto a outras regiões brasileiras. O objetivo desse estudo foi avaliar os parâmetros de qualidade das gomas de tapioca comercializadas na Região Metropolitana do Recife/PE. Foram adquiridas 16 amostras de goma de tapioca em supermercados e realizados os ensaios para detecção de coliforme termotolerante; Bacillus cereus; Salmonella sp.; Contagem Total de Mesófilos; Bolores e Leveduras e Bactérias Láticas. Do total, três amostras apresentaram coliforme termotolerante, onde foram encontrados valores acima da concentração permitida para comercialização. Quanto aos outros patógenos investigados, todas as amostras de gomas apresentaram conformidade dentro de parâmetros previstos em lei. Um achado interessante foi à presença de bactérias láticas em todas as amostras, porque o crescimento deste microrganismo favorece a conservação da goma de tapioca, pela habilidade em produzir ácido láctico, composto que inibe o crescimento da microbiota acompanhante, dentre estes os microrganismos patogênicos.

Palavras-Chave: Manihot, amido, bactérias láticas, coliforme, microorganismos. 


\section{Introdução}

A Mandioca, Manihot esculenta Crantz, é um vegetal que possui raiz tuberosa com aplicação versátil. Possui grande valor alimentar e cultural, de fabricação rústica em grande parte da sua cadeia produtiva e encontrada em todo território nacional. Por exigir tratos culturais simples, é cultivado por muitas famílias em pequenas propriedades para subsistência, em especial no Norte e Nordeste do Brasil, garantindo boa fonte alimentar durante todo o ano (Domene, 2011; EMBRAPA, 2018). A estimativa da produção de Mandioca em 2017 alcançou perto de 21 toneladas no país. Na Região Nordeste, importante mercado produtor e consumidor, a expectativa foi de crescimento de $1,5 \%$ em relação à 2016, sinalizando assim que a economia baseada na Cadeia Produtiva da Mandiocultura se mostra em crescimento nessa região brasileira (IBGE, 2017).

O polvilho é o amido ou a fécula da mandioca produzida em geral de forma artesanal, é extraído por decantação, quando a mandioca crua, descascada e ralada é misturada à água, ainda úmido recebe o nome de goma de mandioca. Depois de seco, transforma-se num pó finíssimo e branco chamado polvilho ou goma (Kovesi et al., 2007). De origem indígena, muito consumida no Nordeste brasileiro, essa fécula é conhecida como goma de mandioca; ingrediente que caracteriza a famosa tapioca, que recheado com raspas de coco fresco e queijo de coalho, fechadas em forma de meia lua e levada a cocção em frigideira rasa; são vendidas no final do dia desde as barraquinhas de esquina até elegantes cafeterias de shoppings.

A mandioca representa um dos principais alimentos energético para milhões de habitantes que vivem nos países em desenvolvimento. Segundo Taco (2011), a composição de cada $100 \mathrm{~g}$ de fécula de mandioca apresenta $17,8 \%$ de umidade; $81,1 \mathrm{~g}$ de carboidrato; 0,5 g de proteína; 0,3 g de lipídeos e 0,6 $\mathrm{g}$ de fibra alimentar. De acordo com Jay (2005), podemos observar que a fécula ou goma de mandioca, tem em sua composição alto percentual de carboidrato e umidade, podendo favorecer o crescimento de microrganismos como as Bactérias
Láticas, Fungos e outros microrganismos patogênicos e deteriorantes. Portanto, o objetivo dessa pesquisa foi avaliar a qualidade sanitária da goma de mandioca, para verificar se esse alimento não representa risco para os comensais, que buscam um alimento isento de glúten.

\section{Material e Métodos}

Foram adquiridas, em supermercados, 16 amostras de diferentes gomas de tapioca, em embalagens íntegras, com $1 \mathrm{~kg}$, e foram codificadas alfanumericamente. Todas as amostras se apresentavam dentro do prazo de validade, importante parâmetro previsto em norma sanitária para comprovação de qualidade e segurança quanto ao consumo e adquiridas no comércio formal na Região Metropolitana do Recife-PE.

Para contagem de Escherichia coli (coliforme termotolerante) e Salmonella sp. (enteropatógeno) foram utilizados kits Compact $D r{ }^{\circledR}$ para teste rápido, metodologias aprovadas pela Codex Alimentarius, I.C.M.S.F., APHA, FDA, ISSO Standards e AOAC para ensaios microbiológicos de alimentos. A quantificação de Contagem Padrão, Bacillus cereus, Bolores e Leveduras e Bactérias Láticas, foram obtidas através da aplicação do método de plaqueamento em profundidade, de acordo com AOAC (2000).

Os ensaios foram realizados em duplicata e o resultado, expresso em unidades formadoras de colônias por grama (UFC. $\mathrm{g}^{-1}$ ) de goma de tapioca.

As análises foram realizadas no Laboratório de Alimentos do Departamento de Tecnologia Rural, na Universidade Federal Rural de Pernambuco.

\section{Resultados}

A presença de Bacillus cereus e Salmonella sp. não foi detectada no estudo (Quadro 1). Entretanto, foram encontrados coliformes termotolerantes que variaram na concentração mínima de $<10$ UFC. ${ }^{-1}$ e máxima de $5,6 \times 10^{3}$ UFC. $g^{-1}$. Nas amostras A6, A9 e A12 foram obtidos valores acima do que preconiza a RDC 12 (Brasil, 2001) (Quadro 1).

Quadro 1. Padrão microbiológico de goma de mandioca segundo os valores de referência da Resolução colegiada da ANVISA (Brasil, 2001). A = Amostra de goma de mandioca. Fonte: Autores (2018).

\begin{tabular}{|c|c|c|c|}
\hline $\begin{array}{c}\text { Amostra/ } \\
\text { Parâmetros }\end{array}$ & $\begin{array}{c}\text { Coliforme } \\
\text { termotolerante } \\
\text { UFC.g }^{-1}\end{array}$ & $\begin{array}{c}\text { Bacillus cereus } \\
\text { UFC. }^{-1}\end{array}$ & $\begin{array}{c}\text { Salmonella } \text { sp. } \\
\text { UFC/25g }\end{array}$ \\
\hline Valor de referência & $\mathbf{1 0}^{3}$ UFC.g-1 & $\mathbf{5 , 0} \mathbf{x 1 0}^{\mathbf{3}} \mathbf{U F C . g}^{-\mathbf{1}}$ & Ausente em 25g \\
\hline A1 & $<10$ & $<10$ & ausente \\
\hline A2 & $<10$ & $<10$ & ausente \\
\hline A3 & $<10$ & $<10$ & ausente \\
\hline A4 & $<10$ & $<10$ & ausente \\
\hline A5 & $<10$ & $<10$ & ausente \\
\hline
\end{tabular}

Shinoharaa, N.K.S.; Padilha, M. de F. do R.; Macêdo, I.M.E.; Nascimento, K.C.B. de L.; Campos, M.V.N. 


\begin{tabular}{|c|c|c|c|}
\hline A6 & $1,7 \times 10^{3}$ & $<10$ & ausente \\
\hline A7 & $<10$ & $<10$ & ausente \\
\hline A8 & $<10$ & $<10$ & ausente \\
\hline A9 & $1,2 \times 10^{3}$ & $<10$ & ausente \\
\hline A10 & $<10$ & $<10$ & ausente \\
\hline A11 & $<10$ & $<10$ & ausente \\
\hline A12 & $5,6 \times 10^{3}$ & $<10$ & ausente \\
\hline A13 & $<10$ & $<10$ & ausente \\
\hline A14 & $<10$ & $<10$ & ausente \\
\hline A15 & $<10$ & $<10$ & ausente \\
\hline A16 & $<10$ & $<10$ & ausente \\
\hline
\end{tabular}

O Quadro 2 apresenta as médias aritméticas dos resultados, em duplicata, para a avaliação dos parâmetros biológicos na verificação da qualidade da goma de tapioca. Nas amostras analisadas, a Contagem Total de Mesófilos apresentou valores que não ultrapassaram a concentração máxima de $5,0 \times 10^{5} \mathrm{UFC} \cdot \mathrm{g}^{-1}$.
$\mathrm{Na}$ avaliação de bolores e leveduras, 10 amostras se mostraram em contagens superiores ao recomendado pela CNNPA $n^{\circ} 12$, que informa como máximo até $10^{3} \mathrm{UFC} \mathrm{g}^{-1}$ (Brasil, 1978). Com relação às bactérias láticas, foi encontrada uma variação de $1,0 \times 10^{2}$ UFC. $\mathrm{g}^{-1}$, como um mínimo de $9,0 \times 10^{5}$ UFC. $\mathrm{g}^{-1}$, como máxima concentração.

Quadro 2. Padrões de qualidade da goma de mandioca, seguindo os valores de referência da Resolução CNNPA nº 12, de 1978 (Brasil, 1978). A = Amostra de goma de mandioca. Fonte: Autores (2018).

\begin{tabular}{|c|c|c|c|}
\hline $\begin{array}{l}\text { Amostra/ } \\
\text { parâmetros }\end{array}$ & $\begin{array}{c}\text { Contagem Total de Mesófilos } \\
\text { UFC. } \text { g }^{-1}\end{array}$ & $\begin{array}{c}\text { Bolores e } \\
\text { Leveduras } \\
\text { UFC.g }^{-1}\end{array}$ & $\begin{array}{l}\text { Bactérias Láticas } \\
\text { UFC.g }{ }^{-1}\end{array}$ \\
\hline $\begin{array}{l}\text { Valor de } \\
\text { referência }\end{array}$ & $\begin{array}{c}\text { Máximo } \\
\text { 5,0 x10 }{ }^{5} \text { UFC.g }{ }^{-1}\end{array}$ & $\begin{array}{c}\text { Máximo } \\
\text { 10 }^{3} \mathrm{UFC}^{-g^{-1}}\end{array}$ & $\begin{array}{c}\text { Ausência de Referência em } \\
\text { Legislação }\end{array}$ \\
\hline A1 & $1,42 \times 10^{4}$ & $2,5 \times 10^{3}$ & $2,8 \times 10^{4}$ \\
\hline $\mathrm{A} 2$ & $6,0 \times 10^{4}$ & $1,32 \times 10^{4}$ & $4,1 \times 10^{3}$ \\
\hline $\mathrm{A} 3$ & $>10$ & 20 & $1,0 \times 10^{2}$ \\
\hline A4 & 40 & 10 & 30 \\
\hline A5 & $2,2 \times 10^{4}$ & $1,72 \times 10^{2}$ & $4,46 \times 10^{5}$ \\
\hline A6 & $3,4 \times 10^{2}$ & $4,7 \times 10^{4}$ & $1,7 \times 10^{3}$ \\
\hline A7 & $3,9 \times 10^{4}$ & $2,83 \times 10^{3}$ & $4,1 \times 10^{4}$ \\
\hline A8 & 20 & $<10$ & 10 \\
\hline A9 & $2,7 \times 10^{3}$ & $4,66 \times 10^{3}$ & $3,8 \times 10^{4}$ \\
\hline A10 & $5,1 \times 10^{4}$ & $3,34 \times 10^{4}$ & $5,6 \times 10^{4}$ \\
\hline A11 & $4,5 \times 10^{2}$ & $2,4 \times 10^{3}$ & $5,3 \times 10^{2}$ \\
\hline A12 & $4,5 \times 10^{5}$ & $3,1 \times 10^{3}$ & $9,0 \times 10^{5}$ \\
\hline A13 & $2,7 \times 10^{2}$ & $8,0 \times 10^{3}$ & $4,8 \times 10^{3}$ \\
\hline A14 & $3,3 \times 10^{3}$ & $1,6 \times 10^{4}$ & $1,3 \times 0^{4}$ \\
\hline A15 & $2,5 \times 10^{4}$ & 10 & $6,8 \times 10^{4}$ \\
\hline A16 & $1,2 \times 10^{4}$ & $5,0 \times 10^{2}$ & $8,2 \times 10^{3}$ \\
\hline
\end{tabular}

\section{Discussão}

A tapioca, derivado da mandioca, emerge nesse contexto como um produto apreciável, primeiramente pela sua descoberta ao nível nacional como um alimento saudável em relação à farinha de trigo, por não conter glúten, e ainda por apresentar grande versatilidade na aplicação culinária (Martins, Costa \& Baptista, 2017). Segundo o IBGE (2018), no Brasil, o consumo em 2017 foi de $14.642 \mathrm{~kg}$ de mandioca por brasileiro, representando importante produto agrícola na alimentação do país, e ainda em termos de área cultivada no território, a mandioca é o sexto alimento em valor de produção.

De acordo com o Quadro 1, observou-se que nas amostras A6, A9 e A12 apresentaram unidades formadoras de colônias para detecção de coliforme termotolerante, estes resultados encontrados estão em desacordo com o que preconiza a legislação em vigor, uma vez que o máximo permitido é $10^{3}$ UFC. ${ }^{-1}$ (Brasil, 2001). Segundo Franco (2012), esse patógeno faz parte da microbiota intestinal dos seres humanos e dos animais de sangue quente. Portanto, quando presente nos alimentos, indica contaminação 
de origem fecal, podendo assim causar graves surtos de grande repercussão na saúde pública.

Ainda de acordo com o Quadro1, observa-se que as 16 amostras da goma de tapioca não apresentaram contaminação por Bacillus cereus e Salmonella sp., indicando que elas obedecem aos padrões de qualidade, em relação a esses patógenos, seguindo a legislação vigente (Brasil, 2001). A ausência desses enteropatógenos nas amostras é um indicativo de que a produção da goma de tapioca encontra-se dentro dos limites aceitáveis.

Apesar da legislação RDC $\mathrm{n}^{\circ} 12$ (Brasil, 2001), não fazer referência à obrigatoriedade quanto à Contagem Total de Mesófilos, Bolores e Leveduras e Bactérias Láticas, nessa pesquisa foi realizada a detecção desses microrganismos, e os resultados estão expressos no Quadro 2. Esses ensaios foram realizados para verificar se a presença de uma microbiota acompanhante poderia deteriorar o produto, mesmo dentro de um prazo de validade estabelecido, tornando o produto impróprio ou representar risco biológico quanto ao seu consumo. Esses parâmetros investigados foram confrontados com a legislação CNNPA no 12 (Brasil, 1978), que previa a determinação desses microrganismos, mas que foi revogada pela RDC 263 (Brasil, 2005), retirando a obrigatoriedade de investigação quanto à presença de Mesófilos e Bolores e Leveduras.

A quantificação encontrada para Bolores e Leveduras, descrita no Quadro 2, foi na ordem de $<10$ UFC. $g^{-1}$ e $4,7 \times 10^{4}$ UFC. $^{-1}$, como mínima e máxima, respectivamente. De acordo com Rodrigues et al. (2015), a presença ou ausência de fungos em alimentos é imprevisível, visto que estes estão amplamente disseminados pelo ambiente, podendo levar a contaminação direta ou cruzada desde a produção, manipulação e armazenamento no campo. No segmento varejista deve-se fazer o uso de embalagens apropriadas, monitoramento constante de infestações, observância às flutuações do clima para o controle de temperatura e umidade durante a guarda, ações que podem evitar uma contaminação biológica posterior, como exemplo, o controle do crescimento fúngico.

Entretanto, a presença de Bolores em alimentos pode acarretar a produção de metabólitos secundários, conhecidos como micotoxinas, e a presença destes, constitui-se um fator de grande risco na saúde pública, pois alguns gêneros, como o Aspergillus e Penicillium podem estar presentes em cereais e tubérculos e são conhecidos por provocar efeitos mutagênicos, teratogênicos e carcinogênicos (Shinohara et al., 2017). Infelizmente, a norma sanitária que regulamenta esse grupo de alimento não prevê a determinação quanto à detecção de Bolores e Leveduras (Brasil, 2001), apesar do risco biológico que podem representar junto aos consumidores, passível de causar grande desordem na saúde pública.

Foram encontrados valores para a contagem total de mesófilos na goma, na faixa mínima inferior

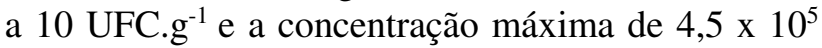
UFC. $^{-1}$ (Quadro 2). Quanto à Contagem Total de Mesófilos em um produto alimentício, a presença deste, reflete a qualidade da matéria-prima, bem como as condições de processamento, manuseio e estocagem, permitindo estimar o tempo de prateleira do alimento em questão e as características sanitárias do produto acabado (Sant'Ana, Conceição \& Azeredo, 2002).

Nesse estudo, observamos que os valores encontrados para Contagem Padrão de Mesófilos, ainda se encontram dentro de parâmetros considerados seguros e próprios para o consumo, baseado na CNNPA n ${ }^{\circ} 12$ (Brasil, 1978). Entretanto, observamos que a amostra A12 no Quadro 2, apresenta crescimento de 4,5 x $10^{5} \mathrm{UFC} \mathrm{g}^{1}$, resultado muito próximo do limite aceitável, que é de 5,0 $\mathrm{x}$ $10^{5} \mathrm{UFC} \mathrm{g}^{-1}$ nessa norma sanitária, ou seja, é um limiar próximo para constituir-se em alimento impróprio para consumo devido a qualidade higiênico-sanitária comprometida.

A presença de Bolores e Leveduras e Bactérias Mesófilas indicam condições higiênicas inadequadas desde a produção, manipulação e produto acabado, mostrando falhas na produção fabril. A busca pela qualidade biológica deve levar em consideração aos aspectos econômicos, pois o alimento contaminado e/ou deteriorado leva a grandes perdas econômicas, ausência ao trabalho e agravos à saúde pública, porque o alimento pode ser um agente de infecção alimentar. Recomenda-se maior rigor nas operacionalizações dos sistemas de boas práticas de fabricação, para que se possa adotar medidas corretivas, visando a produção de um produto de maior qualidade e seguro junto a saúde dos consumidores (Martins \& Martins, 2011).

Foi detectada a presença de Bactérias Láticas na concentração de $1,0 \times 10^{2}$ UFC. $\mathrm{g}^{-1}$ como mínima e máxima na ordem de 9,0 x $10^{5} \mathrm{UFC} \cdot \mathrm{g}^{-1}$. Segundo Sá et al. (2017), apesar de que as legislações vigente (Brasil, 2001) e revogada (Brasil, 1978) para esse grupo de alimento, não preverem a determinação das Bactérias Láticas, a contagem destas bactérias em alimentos amiláceos é importante, porque são produtoras de ácido láctico como o principal metabólito durante a fermentação dos hidratos de carbono, levando a redução do $\mathrm{pH}$ e consequentemente aumento da acidez, contribuindo assim para reduzir a capacidade de desenvolvimento microbiano, principalmente dos patógenos alimentares.

Quando as Bactérias Láticas estão presentes nos alimentos, proporcionam efeitos benéficos para 
os consumidores através de suas propriedades funcionais e tecnológicas. Esses microrganismos têm sido usados como culturas iniciadoras para a fermentação de alimentos e bebidas, devido às suas contribuições para as características sensoriais apreciáveis e pela estabilidade microbiológica em decorrência do crescimento dessas bactérias benéficas (Mota \& Gomes, 2015). Portanto, a presença de Bactérias Láticas se mostra salutar na conservação da goma de tapioca, pois tem efeito protetor contra bactérias deteriorantes e patogênicas pela diminuição do $\mathrm{pH}$, decorrente da produção de ácido láctico.

\section{Conclusão}

A qualidade sanitária da goma foi comprovada pelo atendimento às normas sanitárias definidas na Resolução Colegiada da ANVISA.

O consumo da goma de mandioca representa uma fonte alternativa segura para ingestão de alimento isento de glúten e sem contaminação microbiológica.

\section{Referências}

AOAC. Association of Official Analytical Chemists. 2000. Official Methods of Analysis of AOAC International. 17th edition, Arlington.

BRASIL. 1978. Ministério da Saúde (MS). Comissão Nacional de Normas e Padrões para Alimentos. Resolução - CNNPA nº 12, de 1978.

BRASIL. 2001. Ministério da Saúde (MS). Agência Nacional de Vigilância Sanitária (ANVISA). Resolução RDC n ${ }^{\circ} 12$, de 02 de janeiro de 2001. Regulamento Técnico Sobre os Padrões Microbiológicos para Alimentos. Diário Oficial. Brasília, DF. 10 de janeiro de 2001.

BRASIL. 2005. Ministério da Agricultura, Pecuária e Abastecimento (MAPA). Aprovar o Regulamento Técnico de Identidade e Qualidade dos Produtos Amiláceos Derivados da Raiz de Mandioca. Instrução Normativa ${ }^{\circ} 2$ 2. Disponível: Acesso: 15 de março de 2018.

BRASIL. 2005. Resolução RDC no 263, de 22 de setembro de 2005. Regulamento Técnico para Produtos de Cereais, Amidos, Farinhas e Farelos". ANVISA - Agência Nacional de Vigilância Sanitária.

DOMENE, S. M. A. 2011. Técnica Dietética: Teoria e Aplicações. Rio de Janeiro: Editora Guanabara Koogan.
EMBRAPA. 2018. Empresa Brasileira de Pesquisa Agropecuária. Disponível em:

https://www.embrapa.br/mandioca-e-

fruticultura/cultivos/mandioca. Acesso em: 21 de fevereiro de 2018.

FRANCO, R. M. 2012. Agentes Etiológicos de Doenças Alimentares. Niterói: Editora UFF.

IBGE. 2017. Levantamento Sistemático da Produção Agrícola. Ministério do Planejamento, Orçamento e Gestão. Rio de Janeiro, v. 30, n. 1 p. 1-81.

IBGE. 2018. Instituto Brasileiro de Geografia e Estatística. Disponível em:

https://www.ibge.gov.br/estatisticas-

novoportal/economicas/agricultura-e-pecuaria/9201levantamento-sistematico-da-producao-

agricola.html?\&t=resultados. Acesso em: 20 de fevereiro de 2018.

JAY, J. M. 2005. Microbiologia de Alimentos. Porto Alegre: Editora Artmed.

KOVESI, B.; SIFFERT, C.; CREMA, C.; MARTINOLI, G. 2007. 400g: Técnicas de Cozinha. São Paulo: Companhia Editora Nacional.

MARTINS, L. M. O.; MARTINS, W. M. O. 2011. Parâmetros de Qualidade de Amêndoas de castanha do Brasil comercializadas em Rio Branco-Acre. Revista Brasileira de Tecnologia Agroindustrial, v. 05 , n. 02, p. 542-549.

MARTINS, U.; COSTA, C.; BAPTISTA, M. M 2017. A Valorização da Gastronomia Tradicional no Contexto Turístico: O Caso da Tapioca em Fortaleza. Turismo: Estudos \& Práticas, v. 6, número especial, p. 127-146.

MOTTA, A. S.; GOMES, M. S. M. 2015 Propriedades Tecnológicas e Funcionais de Bactérias Láticas: A importância destes microrganismos para alimentos. Revista do Instituto de Laticínios Cândido Tostes, v. 70, n. 3, p. 172-184.

RODRIGUES, E. B.; ARAÚJO, A. M.; SOBRAL, F. O. S.; ROMÃO, N. F. 2015. Avaliação da Presença de Bolores e Leveduras em Farinha de Mandioca (Manihot esculenta Crantz) Comercializadas a Granel em Feiras Livres do Município de Ji-Paraná-RO. South American Journal of Basic Education, Technical and Technological, v. 2, n. 2, p. 15-22.

SÁ S. A. C. A.; OLIVEIRA JÚNIOR, S. P.; DORES, M. T.; VISÔTTO, L. E.; SILVA, C. R. 
2017. Avaliação das Condições de Aeração do PréInóculo Utilizado no Cultivo de Bactérias Ácido Láticas (Bal) em Meio Líquido. The Journal of Engineering and Exact Sciences, v. 03, n. 06, p. 0835-0840.

SANT'ANA, A. S.; CONCEIÇÃO, C. A.; PERDOMO, D. R. 2002. Comparação Entre os Métodos Rápidos Simplate RTPC- CI e Petrifilm RAC e os métodos convencionais de contagem em placas para a enumeração de aeróbios mesófilos em sorvetes. Food Science and Technology, v. 22, n. 1, p. 60-64.
SHINOHARA, N. K. S.; XIMENES, G. N. C.; CORTES, N. M. S.; SHINOHARA, G. M.; PADILHA, M. R. F. 2017. Pesquisa de Fungos em Farinha de Trigo Comercializada na Região Metropolitana do Recife-PE. Revista Nutrição em Pauta, v. 7, n. 39, p. 43-46.

TACO. 2011. Tabela Brasileira de Composição de Alimentos. $4^{\mathrm{a}}$ ed. Disponível em: http://www.unicamp.br/nepa/taco/contar/taco_4_edi cao_ampliada_e_revisada.pdf $>$ arquivo=taco_4_vers ao_ampliada_e_revisada. pdfAndgt. Acesso em: 09.10.2017. 